\title{
MECHANISM OF PHOTOSYNTHESIS
}

$\mathrm{I}^{\mathrm{N}}$ a recent article (New Phytol., 39, 33; 1940) $\mathrm{K}$. Wohl has presented a notable addition to the literature on the kinetics of photosynthesis in green plants, in which a model is put forward based largely on the results of Emerson, Warburg, and their collaborators. Assuming that the light-sensitive reaction requires 4 quanta $/ \mathrm{mol}$. carbon dioxide, as first demonstrated by Warburg and Negelein, the author suggests the following type of reaction:

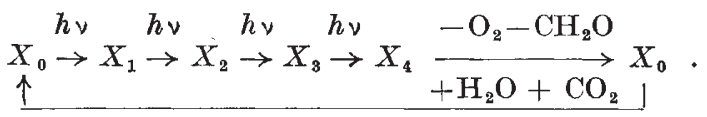

Recent work on quantum efficiency is later reviewed in the paper. The high value of this efficiency and the shape of the rate/light-intensity curve indicate that none of the intermediate photoproducts is lost and that $X_{4}$ is also produced in an irreversible way. The carbon dioxide is therefore considered attached to a 'reducing centre' which is coupled, in an energetic respect, to a number of chlorophyll molecules. Absorbed quanta may then pass to the reducing centre which, together with its associated chlorophyll, may be referred to as a functional photosynthetic unit. Considerations are put forward which support the existence of such a unit, and.a comparison is made with the numerical unit of Emerson and Arnold. Figures are presented both for the functional and the numerical units in a number of plants, calculated from experiments in continuous and in flashing light, and both kinetic and optical models are set up.
As regards the sequence of events figured in (1), experiments in flashing light indicate that the four light processes occur successively with no prolonged dark reaction between. The Blackman reaction $X_{4} \rightarrow X_{0}$, unlike most physiological reactions, deviates widely from the simple Arrhenius reaction. One explanation is that the Blackman reaction occurs in a number of steps of reaction time $\tau_{1}, \tau_{2}$, $\tau_{3}$. . . . Taking two reactions only, for simplicity, $\tau_{1}$ is shown to belong to a reaction of high activation energy and is several orders of magnitude smaller than $\tau_{2}$ which is coupled to a low activation energy. The two reactions are therefore of entirely different types. From the calculated values of $\tau_{1}{ }^{(0)}$ and $\tau_{2}{ }^{(0)}$ (hypothetical reaction times at infinitely high temperatures) the author shows that $\tau_{1}$ relates to a monomolecular reaction and $\tau_{2}$ to a bimolecular. The calculated value $1 / \tau_{1}(0)$ surpasses the theoretical figure even for a monomolecular reaction. This is accounted for by the introduction of an entropy factor $T \triangle S$, replacing the activation energy $A_{1}$ by the free energy $A_{1}-T \Delta S$ in Arrhenius's equation. This gives a figure of the correct order of magnitude only if a considerable number of atomic bonds are broken during the reaction period $\tau_{\lambda}$.

It is suggested that at least six such breakages occur and that the six $\mathrm{CH}_{2} \mathrm{O}$ groups produced combine immediately to, for example, a hexose. These six groups must be produced successively at the same reducing centre, and photosynthesis would then be a 24-quanta process. The bimolecular reaction is taken to be the formation of an oxygen molecule. Ninety-three references are given.

\section{RAIN FOREST OF SOUTHERN NIGERIA}

$\mathrm{D}_{\mathrm{foms}}^{\mathrm{R}}$ R. P. W. RICHARDS, of the Botany School, Cambridge, in a recent paper, states that it forms the first part of the results of the Cambridge Botanical Expedition to Nigeria and it aims at being a description of a typical region of the West African Rain Forest-a chief object being to compare the rain forest of this area with those previously studied in British Guiana and Sarawak ("Ecological Studies on the Rain Forest of Southern Nigeria". (1) "The Structure and Floristic Composition of the Primary Forest", J. Ecology, 27, 1; Feb. 1939. Univ. Press, Cambridge). The reasons for making such a comparison are not stated. The author states on more than one occasion that "the Rain Forest of the whole of South-Western Nigeria is situated near its climatic limits".

Discussing the remarkable uniformity of the forest attributed by Mildbraed to the great climatic changes the region has suffered in the past, causing great migrations of floras and levelling local peculiarities, the author says : "if this is so, it is easy to understand why regions on the extreme edge of the Rain Forest Area, such as South-Western Nigeria, should show a marked poverty in species". This insistence by the author is curious. Perhaps it is based on his statement that "it is generally admitted that the
Cameroons is one of the richest regions of the African Rain Forest and is probably to be regarded as the chief centre of evolution of the Rain Forest flora". Yet the rain forest belt stretches to the west of Nigeria through the Gold Coast and through the French Ivory Coast, where it occupies extensive areas; which, in some parts, are claimed to be as fine examples and to produce as large a percentage of high-quality timber-mahoganies and so forthas any other portion of the belt on the Coast.

The main differences in the author's comparison of the south-western Nigerian forest with that of British Guiana and Sarawak are : (1) that the first and second tree stories in Nigeria are more open, whilst the largest proportion of the third story is true third-story species; (2) the relative floristic poverty of the Nigerian forest; this poverty applying to all three stories of trees, to the shrub and herb layers, and to the climbers and epiphytes. In respect of single species dominance, the author considers the Nigerian rain forest as intermediate between British Guiana and Sarawak. Dr. Richards is of opinion that (1) and (2) above may be due to unfavourable climatic conditions, though with reference to (1) he quite correctly adds "though it is impossible to exclude human interference as a possible cause". 